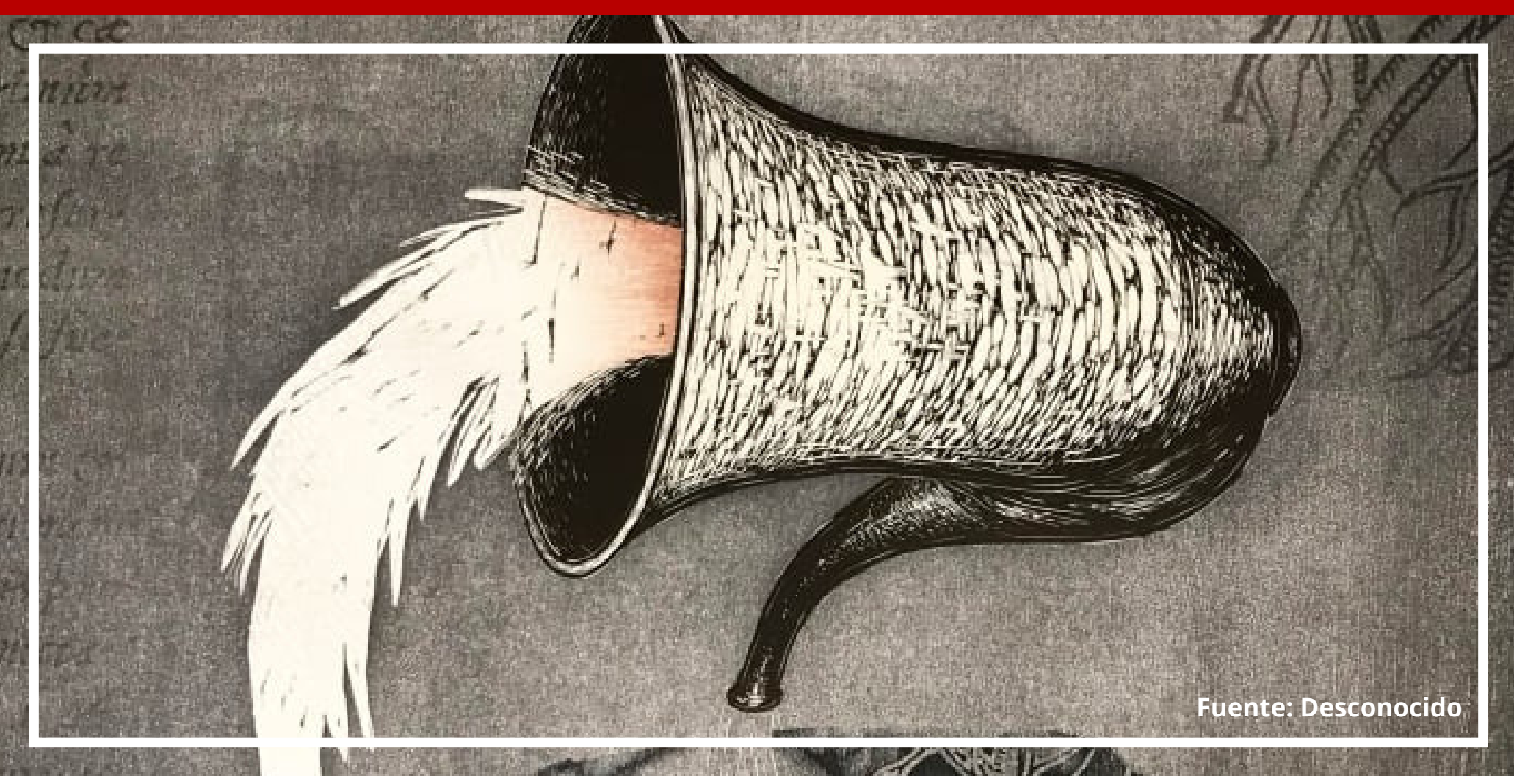

\title{
¿El dióxido de cloro podría ser la panacea universal?
}

doi: $10.52749 /$ rh.v1i1.8

\section{GRACE BEJARANO}

Médico cirujano y psicóloga clínica. Estudió Posgrado en Educación Superior en Universidad San Francisco Xavier de Chuquisaca, Bolivia.

$\checkmark$ psiquegrace13@gmail.com

Resumen. El dióxido de cloro es una sustancia química descubierta en 1914, desde entonces su principal uso fue potabilizar el agua. A inicios de 2020, en la primera ola de la pandemia causada por el SARS-CoV-2, se promocionó esta sustancia como una panacea universal sin tomar en cuenta la diferente fisiopatología de cada enfermedad. A falta de un tratamiento eficaz contra el SARSCoV-2 muchas personas empezaron a consumirlo como tratamiento, generando varios efectos secundarios desde quemaduras en esófago hasta la muerte. Haciendo una revisión de los artículos científicos disponibles se pudo comprobar que no existe evidencia para el uso de dióxido de cloro para ninguna enfermedad, pero sí como desinfectante de superficies.

Palabras clave: Dióxido de cloro, desinfectante de superficies, SARS-CoV-2, pandemia

Cómo citar este artículo:

Bejarano, G. (2021). ¿El dióxido de cloro podría ser la panacea universal? Revista Humanista, 1(1), 47-52. https://doi.org/10.52749/rh.vlil.8

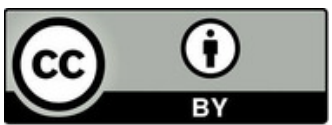

Esta obra está bajo licencia internacional

Creative Commons 4.0 Reconocimiento 4.0. 


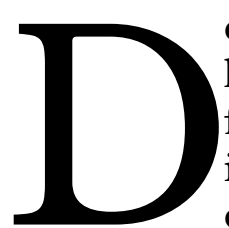
esde el inicio de los tiempos, el ser humano - al encontrarse con la fragilidad de su existencia y por su innata propensión a tratar las dolencias - ha buscado la panacea universal, un medicamento o pócima capaz de sanar casi todas las enfermedades. Por eso, de cuando en cuando, por cientos de años oímos a alguna persona aclamar que descubrió dicha sustancia.

En pleno siglo XXI y mientras se desarrolla la que quizá sea una de las etapas más duras que le ha tocado al ser humano vivir, la pandemia ocasionada por el virus SARS-CoV-2 se ha extendido por casi todos los países y se ha llevado al menos 440000 vidas hasta la fecha. Ante la inminente escalada de los casos, llega de la mano de un descubridor $-y$ miles de sus seguidores - una posible esperanza: el dióxido de cloro. Según sus más fieles adeptos, no solo sirve para tratar todo tipo cáncer, HIV-SIDA, autismo, esclerosis amiotrófica, sino que ahora se plantea su uso también para la infección por covid-19.

¿Desde cuándo se usa el dióxido de cloro?

El dióxido de cloro es un compuesto químico descubierto en 1914 por Sir Humprhy Davy. Desde entonces, se ha estudiado sus posibles usos como la potabilización del agua y el blanqueamiento del papel (Agencia para Sustancias Tóxicas y el Registro de Enfermedades, 2020), pero principalmente nos interesa su acción biocida (Bernarde, Israel , Olivieri, \& Ganstrom, 1965) y virucida (Alvarez \& O'Brien, 1982), pues se ha aplicado como desinfectante en estudios in vitro.

¿Todos los compuestos cuya base es cloro y son promocionados como evidencia de su uso médico son dióxido de cloro?

Existe cierta confusión en cuanto a la clase de compuestos químicos del grupo cloro, a los cuales se les adjudica ser medicamentos ideales para tratar todo tipo de enfermedades. Estos compuestos suelen considerarse bajo la denominación de "dióxido de cloro" (ClO2) solo porque su base es el clorito de sodio (NaClO2), precursor de dióxido de cloro mediante el activador ácido clorhídrico (HCL) añadido a la solución acuosa de clorito de sodio al 25\%. La solución final es comercializada para desinfectar superficies y potabilizar el agua
(Dioxilife, 2020).

Sin embargo, se debe tener en cuenta que el llevar como base el cloro no convierte a estos compuestos en intercambiables o equiparables. Lo mismo sucede con el hidrógeno y el oxígeno: en su forma $\mathrm{H} 2 \mathrm{O}$ es agua potable, pero en su forma $\mathrm{H} 2 \mathrm{O} 2$ es agua oxigenada, muy tóxica para el consumo humano.

Entonces podemos decir que no todos los compuestos cuya base es cloro será dióxido de cloro, pues cada compuesto es diferente y se aplica de diferente manera. Los compuestos más comunes denominados "dióxido de cloro" a los que se les atribuyen propiedades medicinales son:

- El tetraclorodecaoxido (Cl $4 \mathrm{H} 2 \mathrm{O}$ 11) -a partir del cual se produjo el medicamento intravenoso "WF10" usado para la disminuir la carga viral en sangre- fue desarrollado por Oxo Chemie en Suiza como una terapia complementaria para la combinación de regímenes de profilaxis de infecciones antirretrovirales y oportunistas en pacientes con SIDA.

"Los usos investigados por el momento abarcan su presentación tópica" - aplicación directa en piel o mucosas- (Drugs in R\&D, 2004), "hay cierta evidencia que en la presentación de solución inyectable mejora la cicatrización de heridas en pacientes con síndrome del pie diabético" (Maraprygsavan, Mongkolsuk, \& Arnhold, 2016).

- La molécula pequeña estabilizada de clorito de sodio (NaClO2) "NP001" se usa como tratamiento de esclerosis lateral amiotrófica, pues inhibe la expresión de NF-kB y la producción de IL-1ß. Así también, se consideró su uso como regulador inmune de monocitos / macrófagos inflamatorios para disminuir la progresión de la esclerosis lateral amiotrófica, pero solo llegó a la segunda fase de investigación (Miller, Block, \& Katz, 2015), que resultó fallida.

- El ácido hipocloroso (HOCl) es un potente antimicrobiano, es decir, que tiene función biocida pero no es medicamento. "Ha sido sintetizado y estabilizado con potenciales aplicaciones profilácticas y terapéuticas en medicina humana" - desinfectante de heridas y para la eliminación de esporas de 
hongos- (Lafaurie et al., 2015).

Ninguno de los medicamentos anteriormente descritos son dióxido de cloro, sino compuestos diferentes, aunque tengan como base de su composición al cloro, por lo que no serían tomados en cuenta como evidencia del uso medicinal del dióxido de cloro.

\section{¿Cuáles son las acciones del dióxido de cloro?}

El dióxido de cloro, es utilizado en diferentes formas.

La acción biocida - provoca la muerte de microorganismos - del dióxido de cloro como desinfectante de superficies: "actúa principalmente en los receptores de la cápsula viral, lo que inactiva al virus" (Chen \& Vaugh, 1990). Se encontró que "es útil en presencia de E Coli, pero no así en la de Salmonella" (Callejas et al., 2012). Es decir que su acción biocida no está presente frente a todos los microorganismos. También es usado como antiséptico local, en especial para el "posible tratamiento de heridas infectadas" (Noszticzius et al., 2013), y como antiséptico oral en la presentación de enjugue bucal.

El dióxido de cloro usado como desinfectante inactiva los microbios pues desnaturaliza sus proteínas - constituyentes críticas de su integridad y función-gracias a la modificación oxidativa covalente de sus residuos de triptófano y tirosina (Ogata, 2007).

Por otra parte, el dióxido de cloro en el virus de la influenza A desnaturalizó las proteínas de la envoltura viral (hemaglutinina y neuraminidasa) -indispensables para la infectividad del virus - y abolió la infectividad. Luego de aplicar directamente aerosoles de influenza A y dióxido de cloro en gas por 15 min en ratones, se determinó que el dióxido de cloro es efectivo para prevenir la infección por virus de la influenza inducida por aerosol en ratones (Ogata \& Shibata, 2008).

Para su uso en cáncer se aplica principalmente en la presentación de enjugue bucal en el tratamiento de "heridas bucales o llagas relacionadas a la quimioterapia y radioterapia" (Sociedad Americana de Cáncer, 2020) con gran dificultad de cicatrizar (Soolari \& Soolari, 2011), ninguno de estos usos son tratamientos directos de cáncer, sino de las secuelas de la radioterapia. La presentación como enjuague bucal también se usa para tratar la candidiasis, pues daña por permeabilización - mas no por interrupción de su integridad- las membranas plasmáticas de C. albicans. "La fuga de (Potasio) K (+) y la despolarización concomitanteindispensable para la función celular de cualquier microorganismo- de la membrana celular son algunos de los eventos críticos" (Wei $\& \mathrm{Wu}, 2008)$. Es decir, imposibilita que haya un funcionamiento celular "normal" de los microrganismos lo que lleva a su muerte.

$\mathrm{Su}$ acción como antimicrobiano selectivo se debe al tamaño de los organismos: "pocos minutos de contacto en superficies - limitado por la volatilidad del $\mathrm{ClO} 2-$ son suficientes para matar todas las bacterias" (Noszticzius \& Wittmann , 2013).

¿Qué pasa cuando se ingiere agua potabilizada con dióxido de cloro?

Las personas entran en contacto con el dióxido de cloro cuando este es usado para potabilizar el agua las cantidades usadas para este fin son ínfimas. "Su concentración máxima permitida en agua potable es 0.8 miligramos por litro (mg/L) y $1.0 \mathrm{mg} / \mathrm{L}$ del ión de clorito" (Agencia para Sustancias Tóxicas y el Registro de Enfermedades, 2020).

Entre las principales reacciones adversas de la ingesta de dióxido de cloro a través del agua son las siguientes:

Se estudiaron toxicidades subcrónicas periodos largos de ingesta en pequeñas cantidades- de $\mathrm{ClO} 2$ y sus metabolitos, durante 30-60 días de dosis creciente en los monos Cercopithecus aethiops: "El único efecto tóxico inesperado y significativo fue provocado por ClO2; Este químico inhibió el metabolismo de la tiroides en los animales a una dosis de aprox. $9.0 \mathrm{mg} / \mathrm{kg} /$ día. Se produjo una disminución estadísticamente significativa de la tiroxina". (Bercz et al., 1982). Lo que provocaría una enfermedad tiroidea.

En otro estudio el efecto del dióxido de cloro y sus metabolitos, en fetos de ratas expuestos en el útero, "Se observaron algunos casos de riñón hipoplásico, hidronefrosis y dextrocardia en los grupos de tratamiento. El peso fetal aumentó significativamente" (Suh \& Abdel-Rahman, 1983). Este aumento de las malformaciones fetales en estas ratas son problemas de salud que ponen en riesgo la supervivencia de los fetos y el crecimiento aumentado puede llevar a dificultades dentro del parto. 
En experimentos agudos y crónicos que utilizan ratas, ratones y pollos tratados con $\mathrm{ClO} 2, \mathrm{ClO} 2$ y $\mathrm{ClO} 3$ en el agua potable no está exento de efectos secundarios indeseables principalmente el cambio de forma de los glóbulos rojos lo que impide una correcta oxigenación de la sangre y tejidos, provocando anemia por destrucción de la pared de los glóbulos rojos. (Couri \& Abdel-Rahman, 1982).

Se puede decir que los principales efectos nocivos se han demostrado experimentalmente en los glóbulos rojos, la función tiroidea y el desarrollo en animales de laboratorio. "En humanos los grupos que pueden estar en riesgo especial por la desinfección de agua potable con dióxido de cloro están los pacientes que deben someterse a hemodiálisis extracorpórea crónica" (Smith \& Willhite, 1990).

\section{¿Qué es el MMS o CDS?}

La Solución Mineral Milagrosa (MMS o CDS) es la denominación que dio Jim Humble el primer homre en proponer "la mezcla de clorito sódico (NaC102 ) activado con ácido cítrico" (Kalcker, 2016), como cura milagrosa de muchas enfermedades. Es también conocido por ser el fundador dela iglesia del Génesis II, mediante la cual comercializa y promueve el uso medicinal y milagroso de esta sustancia.

En Latinoamérica principalmente, el comercializador de MMS es Andreas Kalker, quien menciona: "ya no utilizamos el ácido cítrico al 50\%, se utiliza el ácido clorhídrico (HCL) al 4\%. Para evitar confusiones, lo vamos a llamar CD (Chlorine dioxide)" (Kalcker, 2016). Cabe mencionar que ninguno de ellos cuenta con acreditaciones profesionales en ningún campo de la salud.

Con esta misma fórmula podemos encontrar comercialmente Dioxlife que lo vende específicamente para desinfectar el agua y superficies, es una Disolución acuosa de Clorito de sodio NaCIO2 al 25\%, sustancia precursora de un biocida (Dióxido de cloro) que se obtiene in situ por acidificación con el ACTIVADOR HCL 4\%. El conjunto consta de dos envases, uno de Clorito Sódico (25\%) y un Activador HCl (4\%) (Dioxilife, 2020).

Desde esta perspectiva podemos notar que no hay diferencia entre el CDS promovido por Kalcker y el desinfectante de agua de Dioxlife. Según Kalcker el CDS seria tratamiento para:
- Apendicitis: "comencé a tomar 3 gotas de MMS por hora hasta las 8 de la mañana. Por la tarde, me hicieron una analítica de sangre y en corto tiempo llegaron los resultados del laboratorio -las marcas inflamatorias volvieron a la normalidad"

- Autismo: Testimonio Dvana "El dióxido de cloro nos cambió la vida porque, además, conociendo todas las aplicaciones que tiene para otras enfermedades. Comenzamos a tomarlo $\mathrm{y}$ todos nos recuperamos de distintas dolencias".

- Calvicie: "Samuel a partir del mes de tomar MMS no solo mejoro de su estado de salud, sino que noto como recuperaba cabello en donde ya solo se apreciaba calvicie”.

- Cáncer colorectal: "diagnosticada de Cáncer de Colon derecho enemas con MMS, combinándolo con MMS2. No fue fácil, tuve mis crisis curativas, pero nunca me rendí siempre tuve mucha $\mathrm{Fe}$ en este Mineral en que me iba a curar" (Kalcker, 2016, pp. 88194).

En libro mencionado lo único que se puede encontrar son testimonios de uso del dióxido de cloro para diferentes enfermedades que dentro de la medicina basada en evidencia tienen un tratamiento efectivo y conocido.

La FDA en cuanto al tratamiento de dióxido de cloro para la infección de SARS-CoV-2 menciona que la ingestión de MMS puede tener las siguientes reacciones adversas (FDA, 2020).

- Insuficiencia respiratoria causada por una condición grave en donde la cantidad de oxígeno que se transporta (metahemoglobinemia)

- Cambios en la actividad eléctrica del corazón (prolongación del QT)

- Baja presión arterial mortal causada por deshidratación

- Insuficiencia hepática aguda

- Conteo bajo de células sanguíneas, debido a la rápida destrucción de los glóbulos rojos (anemia hemolítica), lo que requiere una transfusión de sangre

- Vómitos severos

- Diarrea severa 


\section{Conclusiones}

En tiempos de gran incertidumbre es esperable que aparezcan personas, que promueven tratamientos pseudocientíficos sin evidencia, hilvanando teorías sin lógica ni basadas en ciencia real, por lo cual todos somos susceptibles de caer en el engaño. No existe hasta la fecha ninguna panacea universal para todas las dolencias del ser humano.

Después del análisis expuesto podemos decir que sí, el MMS puede funcionar como desinfectante de superficies y agua en SARSCoV-2 (virus contagioso en el ambiente) ya que su composición es la misma que la comercializada por Dioxilife, pero el MMS no funciona como tratamiento vía oral o endovenosa para infección por Covid -19 (a la fecha febrero de 2021 los datos indican que la transmisión del SARS-CoV-2 es por aire es más importante que por contacto con superficies).

El dióxido de cloro tiene usos comprobados como desinfectante de agua y de superficies, ya que logra desnaturalizar las membranas los microbianas mediante su acción biocida, y como antiséptico en forma de enjuague bucal, en base a cloro se han desarrollado medicamentos que no son el MMS o CDS, como ser el WF10, el FP001 y el ácido hipocloroso, por tanto, no son evidencia de que el MMS se usa de las formas descritas para esos medicamentos.

En la ingesta de dióxido de cloro en el agua desinfectada con este producto, se han evidenciado ciertas reacciones adversas como hemolisis, algunas malformaciones in vivo, alteraciones en el metabolismo de la tiroides,

\section{Referencias}

Agencia para Sustancias Tóxicas y el Registro de Enfermedades. (19 $\begin{array}{llll}\text { de } & 06 & \text { 2020). } & \text { atsdr.cdc.gov. }\end{array}$ https://www.atsdr.cdc.gov/es/phs/es phs160.html

Alvarez, M., \& O'Brien, R. (1982). Mechanisms of Inactivation of Poliovirus by Chlorine Dioxide. Applied and Environmental Microbiology, 44(5), 1064-1071. https://www.ncbi.nlm.nih.gov/pmc/articles/PMC242149/pdf/aem00 180-0060.pdf

Bercz , J., Jones, L., \& Garner, L. (1982). Subchronic Toxicity of Chlorine Dioxide and Related Compounds in Drinking Water in the Nonhuman Primate. Environ Health Perspect, 46, 47-55. https://doi.org/10.1289/ehp.824647.

Bernarde, M., Israel , B., Olivieri, V., \& Ganstrom, M. (1965). Efficiency of Chlorine Dioxide as a Bactericide. Aplied Microbiology, 13(5): 776-780.

Callejas, T., Lopez, F., \& Sbodio, A. (2012). Chlorine dioxide and chlorine effectiveness to prevent Escherichia coli O157:H7. Food Control, 23(2), 325-332. alteraciones en la forma de los glóbulos rojos y fragilidad osmótica, que puede llegar a la anemia en el ser humano.

El MMS o CDS producto promovido por varias personas de dudosa formación, no tiene evidencia real de su uso para ninguna enfermedad, todos los estudios analizados aquí fueron sacados de la mayoría de páginas que promueven la confusión entre los medicamentos existentes como el WF10 y FP001que si tienen evidencia científica para su uso, con el MMS, que no tiene nada que ver con los mencionados medicamentos los cuales tienen regulación y análisis de evidencia para su uso en humanos.

En el caso del MMS o CDS como cita el mismo Kalcker en su libro, la fórmula para el MMS que promueve es la misma que vende Dioxilife y aclara la misma empresa lo comercializa como desinfectante de agua y superficies. No así como medicamento milagroso.

Entre los muchos testimonios plasmados en su libro para un sinfín de enfermedades, sin diferenciar entre enfermedades genéticas, derivadas por patógenos, o de resolución quirúrgica, aplica indistintamente para todas el MMS, lo cual va en contra de toda lógica de la medicina basada en evidencia.

Por lo antes mencionado los entes Reguladores Internacionales como la FDA, sociedades científicas médicas, bioquímicas $\mathrm{y}$ farmacéuticas, no aprobaran el uso vía oral o inyectable en humanos, como lo mencionan los que promueven el MMS como medicamento, porque no cumple ninguno de los requisitos para ensayos clínicos de nuevos fármacos.

Chen, Y., \& Vaugh, H. (1990). Inactivation of human and simian rotaviruses by chlorine dioxide. Applied environmental Microbiology, 1363-1366.

Couri, D., \& Abdel-Rahman, M. (1982). Toxicological Effects of Chlorine Dioxide, Chlorite and Chlorate. Environ Health Perspect, 13-17. https://doi.org/10.1289/ehp.824613.

Dioxilife. (18 de 06 de 2020). Dioxilife. https://www.dioxilife.com/es/clorito-de-sodio/12-clorito-de-sodio140-ml.html

Drugs in R\&D. (2004). WF 10: Macrokine, TCDO, tetrachlorodecaoxide. Pubmed, 242-244. https://doi.org/10.2165/00126839-200405040-00013

FDA. (20 de 06 de 2020). U.S FOOD \& DRUGS. https://www.fda.gov/news-events/pressannouncements/actualizacion-del-coronavirus-covid-19-la-fdaadvierte-empresa-que-comercializa-productos-peligrosos 
Kalcker, A. (2016). La Salud Prohibida. Voedia.

https://escuelafeliz.org/wp-content/uploads/2020/04/La-saludprohibida.pdf

Lafaurie, G. I., Calderón, J., \& Zaror, C. (2015). Ácido Hipocloroso: una Nueva Alternativa como Agente Antimicrobiano y para la Proliferación Celular para Uso en Odontología. International journal of odontostomatology, 475-481. https://scielo.conicyt.cl/scielo.php?script=sci arttext\&pid=S0718$381 \times 2015000300019$

Maraprygsavan, P., Mongkolsuk, J., \& Arnhold, J. (2016). The chlorite-based drug WF10 constantly reduces hemoglobin A1c values and improves glucose control in diabetes patients with severe foot syndrome. J Clin Transl Endocrinol, 53-58. https://www.ncbi.nlm.nih.gov/pmc/articles/PMC5680448/

Miller, R., Block, G., \& Katz, J. (2015). Randomized phase 2 trial of NP001, a novel immune regulator. American Academy of Neurology. https://nn.neurology.org/content/2/3/e100.short

Noszticzius , Z., \& Wittmann , M. (2013). Chlorine Dioxide Is a SizeSelective Antimicrobial Agent. PLoS One. https://doi.org/10.1371/journal.pone.0079157.

Noszticzius , Z., Wittmann, M., \& Kály-Kullai, K. (2013). Chlorine Dioxide Is a Size-Selective Antimicrobial Agen. PLoS One.

Ogata, N. (2007). Denaturation of Protein by Chlorine Dioxide: Oxidative Modification of Tryptophan and Tyrosine Residues. ASC Publications, 4898-4911. https://pubs.acs.org/doi/10.1021/bi061827u

Ogata, N., \& Shibata, T. (2008). Protective Effect of LowConcentration Chlorine Dioxide Gas Against Influenza A Virus Infection. J Gen Virol, 60-67. https://doi.org/10.1099/vir.0.83393$\underline{0 .}$
Pubchem. (19 de 06 de 2020). Pubchem. https://pubchem.ncbi.nlm.nih.gov/compound/Tetrachlorodecaoxid e\#section=Mechanism-of-Action

Shinada, K., Ueno, M., \& Konishi, C. (2010). Effects of a mouthwash with chlorine dioxide on oral malodor and salivary bacteria: a randomized placebo-controlled 7-day trial. Trials, 11-14.

Smith, R., \& Willhite, C. (1990). Chlorine Dioxide and Hemodialysis. Regul Toxicol Pharmacol, 42-62. https://doi.org/10.1016/02732300 (90) $\underline{90006-\mathrm{w} .}$.

Sociedad Americana de Cáncer. (18 de 06 de 2020). cancer.org. https://www.cancer.org/es/tratamiento/tratamientos-y-efectossecundarios/efectos-secundarios-fisicos/problemas-de-laboca/llagas-en-la-boca.html

Soolari, N., \& Soolari, A. (2011). Closure of an Open Wound Associated with Bisphosphonate-Related Osteonecrosis of the Jaw in a Breast Cancer Patien. Open Dent J, 163-167.

Suh , D., \& Abdel-Rahman, M. (1983). Effect of Chlorine Dioxide and Its Metabolites in Drinking Water on Fetal Development in Rats. J Appl Toxicol, 75-79. https://doi.org/10.1002/jat.2550030204.

Veerasarn, V., Khorprasert, C., \& Lorvidhaya, V. (2004). Reduced Recurrence of Late Hemorrhagic Radiation Cystitis by WF10 Therapy in Cervical Cancer Patients: A Multicenter, Randomized, Two-Arm, Open-Label Trial. Pubmed. https://pubmed.ncbi.nlm.nih.gov/15542165/

Wei, M., \& Wu, K. (2008). Plasma Membrane Damage to Candida Albicans Caused by Chlorine Dioxide (ClO2). Lett Appl Microbiol, 67-73. https://doi.org/10.1111/j.1472-765X.2008.02387 